\title{
Characteristics of magnetic dipolarizations in the vicinity of the substorm onset region observed by THEMIS
}

\author{
SuPing Duan ${ }^{1 *}$, Chi Wang ${ }^{1,2}$, Weining William Liu ${ }^{1}$, and ZhaoHai He ${ }^{1}$ \\ ${ }^{1}$ State Key Lab of Space Weather, National Space Science Center, Chinese Sciences Academy, Beijing 100190, China; \\ 2University of Chinese Academy of Sciences, Beijing 100049, China

\section{Key Points:} \\ - Dipolarization in the substorm onset region has a large beginning elevation angle $\left(>60^{\circ}\right)$ followed by significant magnetic \\ fluctuations. \\ - Dipolarization outside the substorm onset region has multi-step increases in the elevation angle with a small beginning elevation \\ angle $\left(<45^{\circ}\right)$. \\ - A new indicator is proposed to identify the substorm onset location.
}

Citation: Duan, S. P., Wang, C., Liu, W. W. and He, Z. H. (2021). Characteristics of magnetic dipolarizations in the vicinity of the substorm onset region observed by THEMIS. Earth Planet. Phys., 5(3), 239-250. http://doi.org/10.26464/epp2021031

\begin{abstract}
With conjunction observations of electromagnetic fields and plasma from Time History of Events and Macroscale Interactions during Substorm (THEMIS) in the near-Earth magnetotail, we investigate the spatial and temporal properties of substorm dipolarizations in the near-Earth plasma sheet (NEPS) during a substorm at 03:23 UT on 12 February 2008. Substorm dipolarizations with different features are detected by three near-Earth THEMIS probes (THA (P5), THD (P3) and THE (P4)) in the magnetotail. In the current sheet with a large plasma beta value $(\beta>2$, where $\beta$ is the ratio of the plasma thermal pressure to the magnetic pressure), the dipolarization within the substorm onset region, $(-10.4,2.8,-2.6) R_{\mathrm{E}_{-} \mathrm{gsm}}$, has a large initial magnetic field elevation angle, $\theta>60^{\circ}, \theta=\arctan \left(B_{z} /\left(B_{x}{ }^{2}+B_{y}{ }^{2}\right)^{1 / 2}\right)$, and is accompanied by energetic ion (tens to hundred keV) dispersionless injection detected by THD (P3). This substorm onset dipolarization is characterized by $B_{x}$ and $B_{y}$ components around $0 \mathrm{nT}$ with significant fluctuations. The $B_{z}$ component increases sharply and its subsequent magnitude approaches the total magnetic field, $B_{\mathrm{t}}$. The maximum value of the elevation angle approaches $85^{\circ}$ during the later substorm expansion phase. In the NEPS with $\beta \sim 1$, the dipolarization outside the substorm onset region is characterized by a magnetic elevation angle with a small beginning value of $\theta<45^{\circ}$ and following multi-step enhancements during the substorm expansion phase. The maximum value of the elevation angle approaches to $70^{\circ}$ during the later substorm expansion phase. Our observation results indicate that characteristics of dipolarization with a large beginning elevation angle within the substorm onset region provide a new indicator to identify substorm onset location.
\end{abstract}

Keywords: substorm; magnetic dipolarization ; near-Earth plasma sheet; magnetotail

\section{Introduction}

Substorm dipolarization plays a key role in substorm expansion onset in the near-Earth plasma sheet in the magnetotail. It is well known that substorm dipolarization is accompanied with an intense induced electric field during the substorm expansion phase (e.g., Takahashi et al., 1987; Baumjohann et al., 1999; Lui, 1996; Maynard et al., 1996; Duan SP et al., 2011, 2012, 2016). This large induced electric field is associated with current disruption or diversion, and sharply accelerates ions and electron at the inner edge of the plasma sheet during substorm expansion onset (e.g., Cao JB et al., 2011; Dai L et al., 2014, 2015; Sun XY et al., 2019). The induced electric field caused by substorm dipolarization within

Correspondence to: S. P. Duan, spduan@nssc.ac.cn

Received 04 FEB 2021; Accepted 15 APR 2021.

Accepted article online 09 MAY 2021.

(C)2021 by Earth and Planetary Physics. the substorm onset region can give rise to ion and electron dispersionless injection (e.g., Reeves et al., 1990; Liu WW et al., 2007; He ZH et al., 2016). It may be worthy to note that, in addition to dispersionless injections, dispersed injections can also be generated by dipolarization, as suggested by Duan AY et al. (2014), and Liu CM and Fu HS (2019). Although substorms have been investigated for many decades, the detailed features of magnetic dipolarization in the vicinity of the substorm onset location are still not very clear.

There are multiple magnetic dipolarizations during the substorm expansion phase in the near Earth tail plasma sheet (e.g., Duan SP et al., 2011, 2016; Lui et al., 2008). It should be clear that the dipolarization front is a special structure in the magnetotail and is usually accompanied by the bursty bulk flow (e.g., Nakamura et al., 2002, 2009; Lui et al., 2008; Runov et al., 2009; Fu HS et al., 2012). Among these multiple dipolarizations, which one is associated with substorm onset has not been clear until now. It would 
be better if the threshold of magnetic field polarization could be given to judge the occurrence and onset time of substorms. However, dipolarization signatures within the substorm expansion onset region are rarely reported.

Previous research has suggested that the substorm expansion onset region is located on dipole-like field lines near $X \sim-10 R_{\mathrm{E}}$ in Earth's magnetotail (e.g., Kaufmann, 1987; Samson et al., 1992; Lui et al., 1999). The region of substorm expansion onset is located at the inner edge of the current sheet (e.g., Lui and Burrows, 1978; Nagai, 1982; Lui, 1996). Lui and Burrows (1978) pointed out that the substorm triggering process occurred on closed magnetic field lines at the inner edges of the plasma sheet. Samson et al. (1992) proposed that field line resonances (FLR) played a role in substorm intensifications. Low frequency waves, especially kinetic Alfvén waves, may trigger substorm onset in the inner edge of the near-Earth plasma sheet (e.g., Samson et al., 1992; Lui et al., 1999; Liang et al., 2008; 2009; Duan SP et al., 2012). Maynard et al. (1996) pointed out that the substorm onset region is in the vicinity of the inner edge of the plasma sheet of the near-Earth magnetotail, and the ripples associated with the dusk-dawn electric field occurred before the beginning of the dipolarization. At substorm onset, large electric field fluctuations are associated with the onset of magnetic field variation.

Single point in situ detection cannot clearly distinguish the difference between magnetic dipolarizations at the substorm expansion onset location and its outer regions in the near-Earth plasma sheet. The THEMIS mission provides a good dataset to investigate the spatial and temporal features of magnetic dipolarizations during the substorm process. Our paper presents observational evidence to illustrate the various properties of substorm dipolarizations, using three THEMIS near-Earth probes on 12 February 2008.

\section{Observations}

The substorm onset trigger process is one of the major objectives of the THEMIS mission (Angelopoulos, 2008). In our investigations, the three near-Earth probes THEMIS-D (THD), THEMIS-E (THE) and THEMIS-A (THA) are used to investigate the detailed characteristics of substorm dipolarizations in the vicinity of the substorm onset region in the NEPS. Data from the electrostatic analyzer (ESA) (McFadden et al., 2008), flux gate magnetometer (FGM) (Auster et al., 2008), electric field instrument (EFI) (Bonnell et al., 2008) and the solid state telescope (SST) are used in our analysis. The detailed magnetic dipolarization features of a substorm on 12 February 2008 are presented below, using the geocentric solar magnetospheric (GSM) coordinate system.

\subsection{Identification of 03:23 UT Substorm Onset Time}

Figure 1 shows the $A E, A U$ and $A L$ index from 02:00UT to 05:00 UT on 12 February 2008. The substorm onset time is around 03:23 UT as marked by the first vertical dashed line. According to the THEMIS ground-based auroral all-sky imager at the KUUJ station (magnetic local time $(M L T) \sim 23.2$, magnetic latitude $(M L a t) \sim 66.9$ degree) auroral brightening occurs at 03:23UT near the equatorward edge of the auroral region after which the auroral arc expands to the high latitude region. $A E$ index and aurora data both indicate that the substorm onset time is at 03:23 UT on 12 February 2008. The second vertical dashed line marks a substorm enhancement at 03:30 UT during the substorm expansion phase.

\subsection{Orbits of Three Near-Earth THEMIS Probes}

Figure 2 shows three near-Earth THEMIS probe orbits for THE (P4, blue line), THD (P3, green line) and THA (P5, purple line) during the period from 03:00 UT to 05:00 UT on 12 February 2008. These three probes were located in the near-Earth magnetotail around $X \sim-10 R_{\mathrm{E}}$ and $Z \sim-2.5 R_{\mathrm{E}}$. THD (P3) and THE (P4) are both located in the pre-midnight region with positive $Y \sim 2.8 R_{\mathrm{E}}$ and $Y \sim 3.5 R_{\mathrm{E}}$, respectively. THA (P5) is located post-midnight with negative $Y \sim$ $-0.3 R_{\mathrm{E}}$. Two probes located in the dusk sector, THD and THE, both move in the tailward direction as marked by the green and blue arrows in Figure 2, respectively. On the other hand, the dawn sector probe THA moves towards the Earth, as marked by the purple arrow in Figure 2.

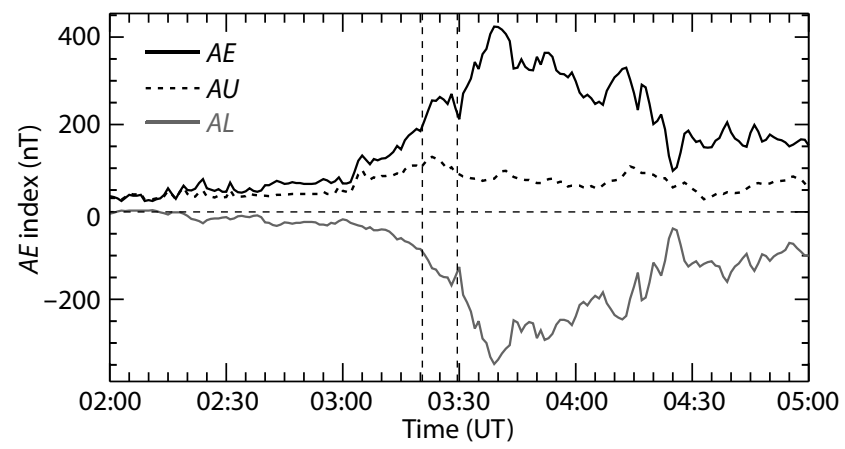

Figure 1. The $A E$ index in the interval from 03:00UT to 05:00 UT on 12 February 2008. The first vertical dashed line marks the substorm onset time at 03:23 UT. The second vertical dashed line marks a substorm enhancement at 03:30 UT during this substorm expansion phase.
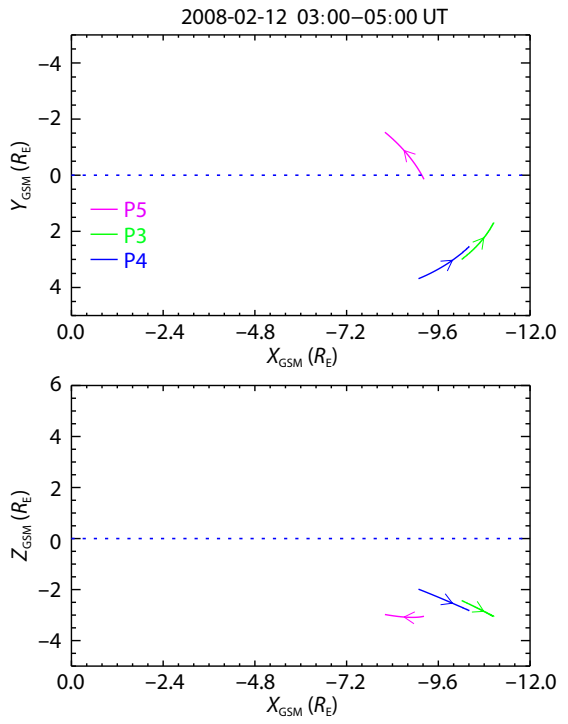

Figure 2. The orbits of three near-Earth THEMIS spacecraft, P3, P4 and P5, during the interval from 03:00UT to 05:00 UT on 12 February 2008. The arrows mark the direction of spacecraft motion. 


\subsection{Conjunction Observations of Dipolarization Features in the Vicinity of Substorm Onset}

Figure 3 displays the plasma and magnetic parameters detected by THD (P3) during the substorm with onset time at 03:23 UT on 12 February 2008. From top to bottom, panels show (a) ion number density (black line), $N_{\text {ion }}$ in $\mathrm{cm}^{-3}$ and temperature $0.1 T_{\text {ion }}$ in $\mathrm{keV}$

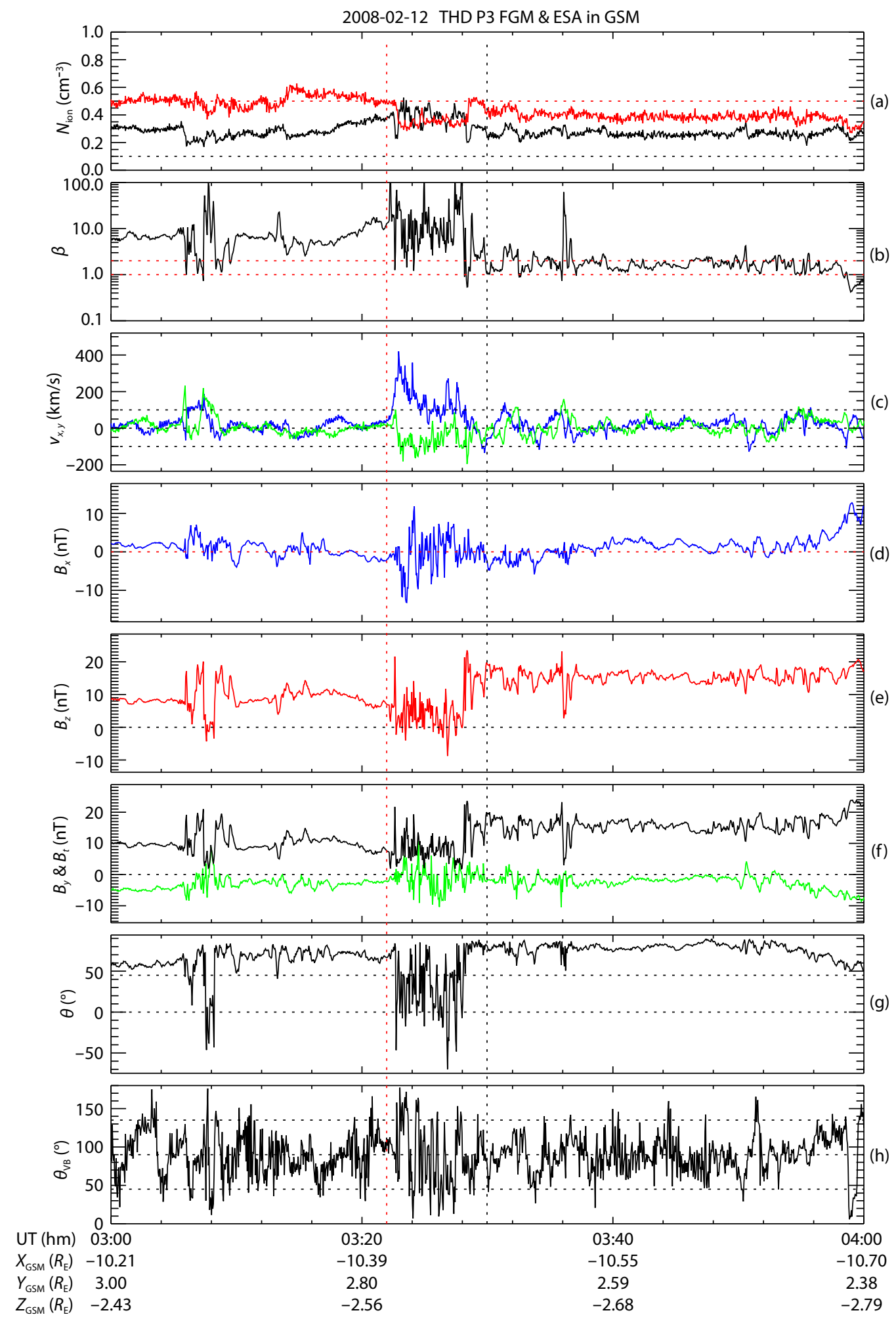

Figure 3. Plasma and magnetic field data from the near-Earth THEMIS probe THD/P3. From top to bottom, the panels show (a) ion number density (black line) and temperature ( $0.1 T_{\text {ion }}$ red line, in keV unit), (b) the plasma beta value, (c) the $X$ (blue) and $Y$ (green) components of the ion bulk flow speed, (d) $B_{x}$ component of magnetic field, (e) $B_{z}$ (f) $B_{y}$ (green line) and the total magnitude value $B_{\mathrm{t}}$ (black line), (g) the magnetic field elevation angle, $\theta$, and $(\mathrm{h})$ the angle between the magnetic field and velocity, $\theta_{\mathrm{VB}}$. 
unit, (b) the plasma beta value, $\beta$ (beta is the ratio of the plasma thermal pressure to the magnetic pressure), (c) the $x$ and $y$ components of ion bulk velocity, $v_{x}$ (blue), $v_{y}$ (green), (d) the $B_{x}$ component of the magnetic field, (e) the $B_{z}$ component of the magnetic field, (f) the $B_{y}$ component (green line) and the total magnitude value (black line) of the magnetic field, $(\mathrm{g})$ the magnetic field elevation angle, $\theta$, and (h) the angle between ion bulk flow and the magnetic field, $\theta_{\mathrm{VB}}$. Marked by the red dotted vertical line, the in situ substorm onset time is at 03:22 UT, $1 \mathrm{~min}$ ahead of the $A E$ index and substorm auroral onset time 03:23 UT. At the substorm expansion beginning time, ion number density sharply increases from $0.2 \mathrm{~cm}^{-3}$ to $0.5 \mathrm{~cm}^{-3}$, but ion temperature suddenly decreases from $5 \mathrm{keV}$ to $3 \mathrm{keV}$ as shown in Figure 3a. The plasma beta value is several tens before substorm onset and becomes disturbed largely after the substorm onset time with large values, usually $>2$ as shown in Figure $3 \mathrm{~b}$. Figure $3 c$ presents that ion burst bulk flow is observed near substorm onset, $v_{\text {ix }} \sim 300 \mathrm{~km} / \mathrm{s}$. Figure $3 \mathrm{~d}$ and $3 \mathrm{f}$ show that the $B_{x}$ component is close to zero and with very small total magnetic field magnitude $\left(B_{\mathrm{t}} \sim 10 \mathrm{nT}\right)$ before substorm onset. The high $\beta$ value and weak magnetic field $B_{\mathrm{t}}$ both demonstrate that THD (P3) is located in the near-Earth current sheet (NECS) (e.g., Cao JB et al., 2006) approaching its apogee $(-10.4,2.8,-2.6) R_{\mathrm{E}}$ as shown by the value at the bottom of Figure 3. Figure $3 e$ presents that the $B_{z}$ component is around $10 \mathrm{nT}$ before substorm onset, which then fluctuates intensely with broadband frequency during the early substorm expansion phase. After substorm onset the $B_{y}$ component fluctuates significantly near the zero central line. Figure $3 \mathrm{~g}$ shows the magnetic field elevation angle is very large, approaching $70^{\circ}$ before substorm expansion onset. The high magnetic field elevation angle and dominant $B_{z}$ component both demonstrate that THD is located at the dipole-like field line region and in the vicinity of the inner edge of the NECS. After the substorm expansion onset time, the plasma density, beta, velocity and the magnetic field all have significant disturbances with broadband frequency. These distinct fluctuations last about 6 min from 03:22 UT to 03:28 UT.

Accompanying THD (P3) located in the NECS, THE (P4) is located in the earthward central plasma sheet with a larger $Y$ value. Figure 4 displays the plasma and magnetic parameters detected by THE (P4) during this substorm on 12 February 2008, formatted the same as Figure 3 . The red dotted vertical line also marks the substorm expansion onset time, at 03:23 UT. Figure 4a shows the ion density sharply increased from $0.2 \mathrm{~cm}^{-3}$ to $0.45 \mathrm{~cm}^{-3}$, but ion temperature suddenly decreased from $5.5 \mathrm{keV}$ to $3 \mathrm{keV}$. The plasma beta value was less than 10 before substorm expansion onset and then significantly fluctuated between 1 and 100 after the substorm onset time with a large value, usually $>1$ as shown in Figure 4b. Figure 4c presents that the ion bulk flow changes in direction from earthward to tailward after substorm onset. Figure $4 \mathrm{~d}$ shows that the $B_{x}$ component is about $5 \mathrm{nT}$ before the substorm onset time and then fluctuates significantly. The positive $B_{x}$ component indicates that THE (P4) is located northward of the current sheet in the near-Earth magnetotail. Figure $4 \mathrm{e}$ shows the $B_{z}$ component is about $10 \mathrm{nT}$ before the substorm onset time and then also fluctuates during the early substorm expansion phase. Figure $4 \mathrm{f}$ shows the total $B$ magnitude value (black line) is about $12 \mathrm{nT}$ and the $B_{y}$ component is $\sim-5 \mathrm{nT}$ before substorm onset.
After substorm onset the $B_{y}$ component fluctuates with mainly negative values. Figure $4 \mathrm{~g}$ shows that the magnetic field elevation angle detected by P4 is high, approaching $50^{\circ}$ before substorm onset. After the substorm onset time, plasma number density, beta, velocity and the magnetic field all have large disturbances. These clear fluctuations last about $7 \mathrm{~min}$ from 03:23 UT to 03:30 UT.

The plasma and magnetic parameters detected by THA (P5) during the 03:23 UT substorm on 12 February 2008 are presented in Figure 5 formatted as in Figure 3. The red dotted vertical line also marks the in situ substorm onset time, at 03:22 UT. Figure 5a shows ion density and temperature both slightly increase after substorm onset. The plasma beta value is $\sim 1$ around the substorm onset time with no clear change as shown in Figure $5 \mathrm{~b}$. Figure $5 c$ presents the ion bulk flow which is very slow, approaching zero near substorm onset time. Figure $5 \mathrm{~d}$ shows that the $B_{x}$ component is $\sim-18 \mathrm{nT}$ around substorm onset time and then decreases to $-25 \mathrm{nT}$ after substorm onset. The negative large $B_{x}$ component indicates that THA (P5) is located southward of the current sheet in the near-Earth magnetotail. Figure 5 e presents the $B_{z}$ component is about $10 \mathrm{nT}$ around substorm onset time. It does not increase during the early expansion phase until after 03:30 UT. Figure $5 f$ shows the total $B$ magnitude value (black line) is about $25 \mathrm{nT}$ and the $B_{y}$ component is around $-5 \mathrm{nT}$ before substorm onset. After substorm onset the $B_{y}$ component has no clear fluctuations. Figure $5 \mathrm{~g}$ shows the magnetic field elevation angle detected by $\mathrm{P} 5$ is $\sim 35^{\circ}$ at substorm onset and then remains low after substorm onset.

The second dotted dashed line in Figures 3-5 marks the substorm enhancement at 03:30 UT, as shown by the second vertical line in Figure 1 of the $A E$ index. THD, THE and THA all observe increases in the $B_{z}$ component and magnetic elevation angle at the same time 03:30 UT; the largest increase in the magnetic elevation angle is detected by THA from $30^{\circ}$ to $65^{\circ}$, while THE increases from $60^{\circ}$ to $70^{\circ}$. A very slight increase in the elevation angle in the inner edge of the NECS is observed by THD $\sim 85^{\circ}$, since it is located in the current sheet within the substorm onset region. The distances between THD and THE, THD and THA are $(\mathrm{d} X, \mathrm{~d} Y, \mathrm{~d} Z)=$ $(0.9,0.6,0.3) R_{\mathrm{E}}$ and $(1.3,3.0,0.5) R_{\mathrm{E}}$, respectively. These distances show that the dipolarization of substorm enhancement during the substorm expansion phase has a large spatial scale of several $R_{\mathrm{E}}$. The duration of enhancement dipolarization lasts about ten minutes as shown in Figure $5 \mathrm{~g}$.

During substorm dipolarizations the electric field has large fluctuations as shown in Figure 6. From top to bottom, the panels present three components of electric field $E_{x}$ (blue), $E_{y}$ (green) and $E_{z}$ (red) from THD, THE, and THA, respectively. The largest amplitude of electric field fluctuations at substorm onset is detected by THD at 03:22 UT, $E_{y} \sim 15 \mathrm{mV} / \mathrm{m}$, as shown in first panel in Figure 6. One minute later for THE and seven minutes later for THA, the probes detected significant electric field fluctuations as presented in the second panel, $E_{y} \sim 3 \mathrm{mV} / \mathrm{m}$, and bottom panel, $E_{y}$ $\sim 6 \mathrm{mV} / \mathrm{m}$, respectively. Accompanying the significantly intense electric field, $E_{y} \sim 15 \mathrm{mV} / \mathrm{m}$, THD detected energetic ion dispersionless injection as presented in Figure 7a at 03:22 UT. At substorm enhancement around 03:30 UT, all three probes detect in- 


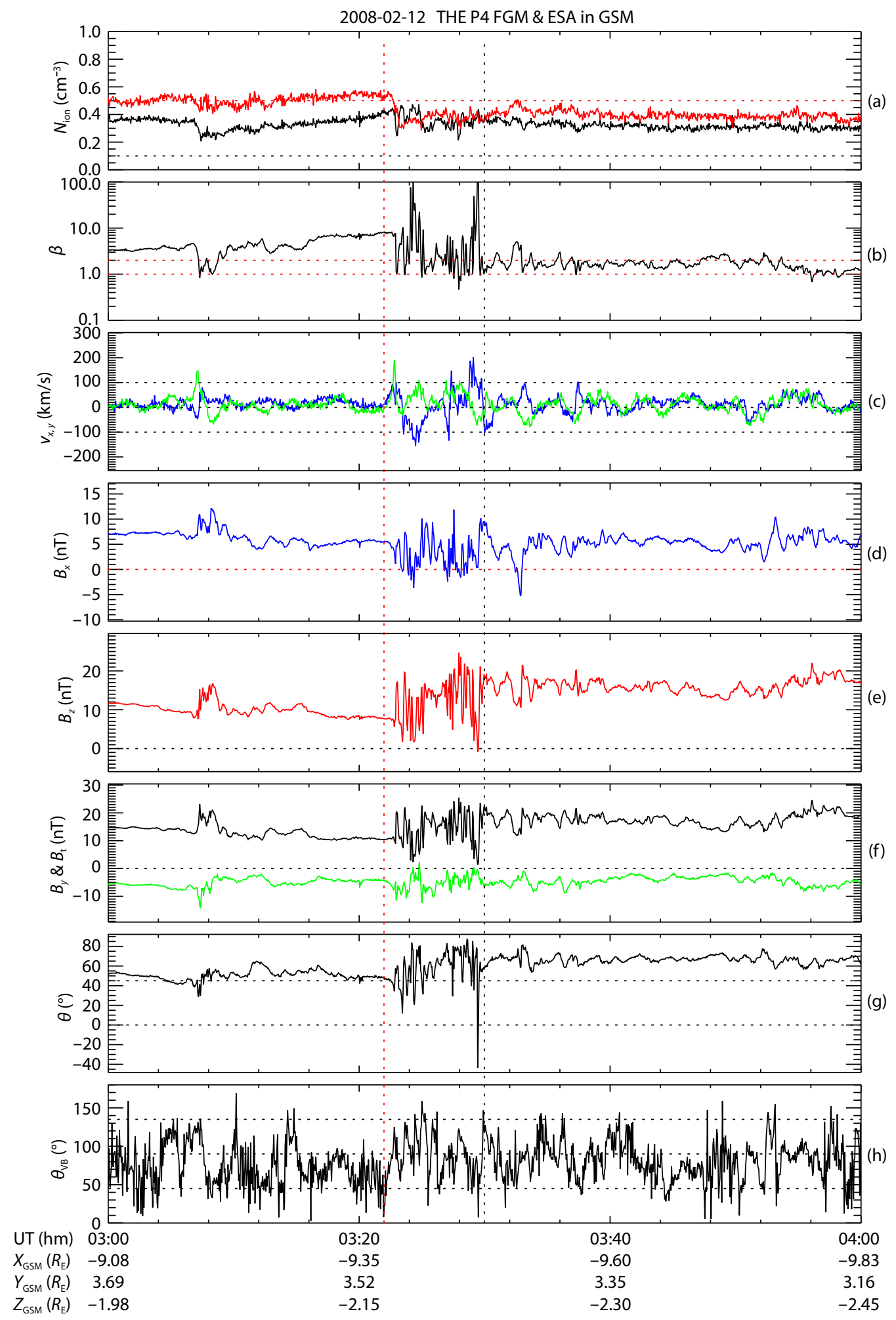

Figure 4. Plasma and magnetic field data from the near-Earth THEMIS probe THE/P4. The figure format is the same as Figure 3.

tense electric field. Accompanying these intense electric fields, energetic ion dispersion injections are all detected by THD, THE and THA, as marked by the second vertical line in Figure 7. On the other hand, the significant magnetic field fluctuations detected by THD within the substorm onset region are characterized by broadband frequency as shown in the top three panels, $\delta B_{\text {xp } 3}, \delta B_{\text {yp } 3}$ and $\delta B_{z p 3}$ in Figure 8. The largest amplitude of magnetic field fluctu- ations, $\delta B \sim 10 \mathrm{nT}$, is also detected by THD approaching the substorm onset location. The weak magnetic oscillations detected by THA are presented in the bottom three panels in Figure 8.

\section{Discussion}

The above conjunction observations by three near-Earth THEMIS 

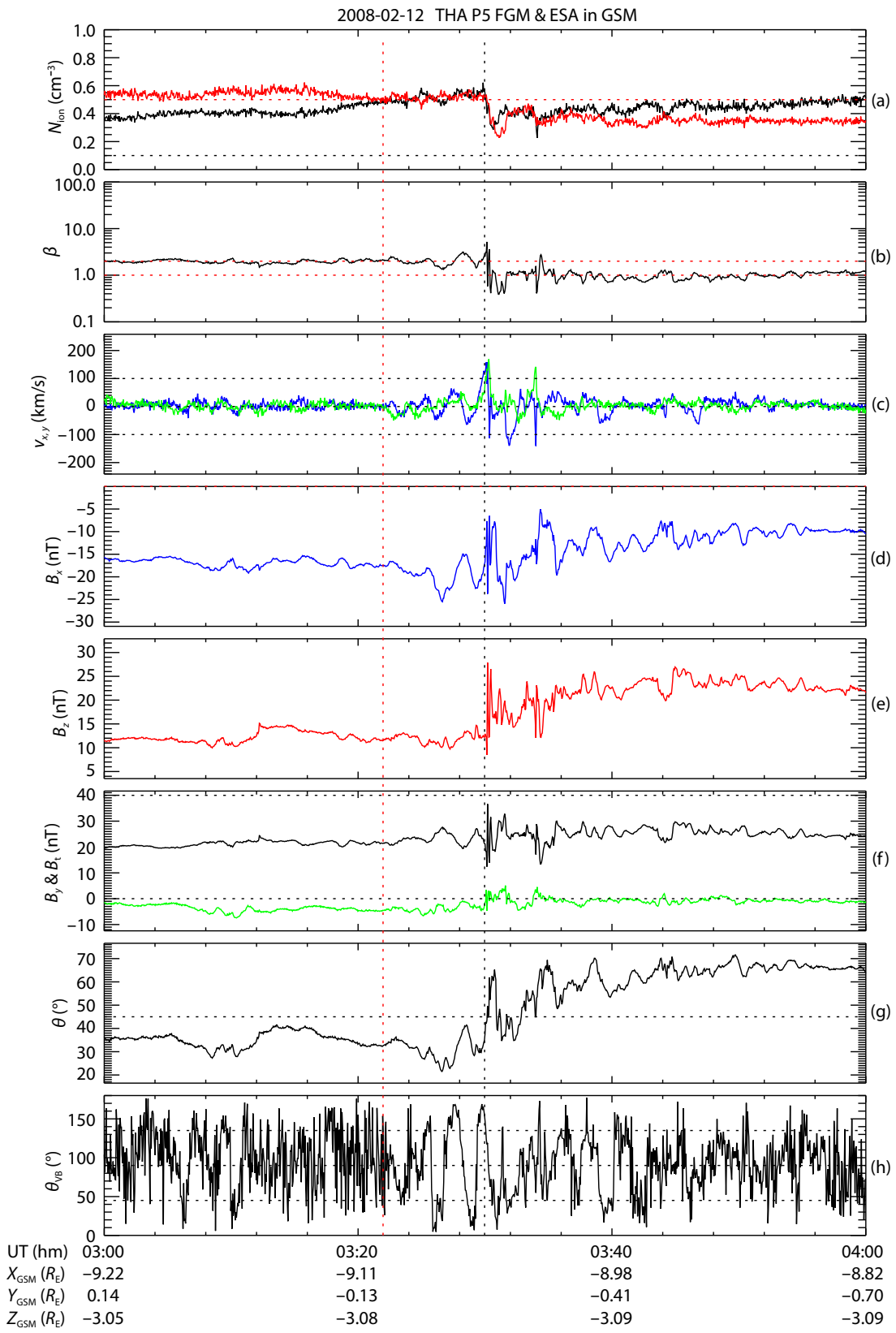

Figure 5. Plasma and magnetic field data from the near-Earth THEMIS probe THA/P5. The figure format is the same as Figure 3.

probes present clear features of magnetic dipolarization in the vicinity of the substorm onset region, accompanied by large and steady beginning elevation angle, $>60^{\circ}$ and energetic ion dispersionless injection marked by the first vertical lines in Figure $3 \mathrm{~g}$ and Figure 7a. After substorm onset time, the significant magnetic fluctuations occurred at the inner edge of near-Earth current sheet. The high magnetic field elevation angle at the beginning of the dipolarization means that the substorm onset location is at the inner edge of the plasma sheet with a dipole-like magnetic field. This result is consistent with previous research results (e.g., Lui and Burrows, 1978; Samson et al., 1992; Maynard et al., 1996). Lui and Burrows (1978) pointed out that the substorm triggering process occurred on closed magnetic field lines at the inner edges of the plasma sheet. Samson et al. (1992) proposed that the field line resonance triggered the substorm onset in the near-Earth cur- rent sheet. Within the substorm onset region, significant electromagnetic field oscillations with broadband frequency are indeed observed by the near-Earth THD probe as shown in the first three panels in Figure 8.

The broadband fluctuations are observed in the substorm onset region in the near-Earth central plasma sheet as shown in the top three panels in Figure 8. These broadband fluctuations are associated with FLRs in the substorm onset region exhibiting complex features with propagation in different directions, usually in the azimuthal and radial directions. Wharton et al. (2019) reported that the eigenfrequencies of any magnetic flux tube depended upon its length, the variation of the Alfvén speed along the flux tube, and the wave polarization. The Alfvén speed is determined by the local plasma mass density and local magnetic field strength. The magnetic field power spectral density in the inter- 


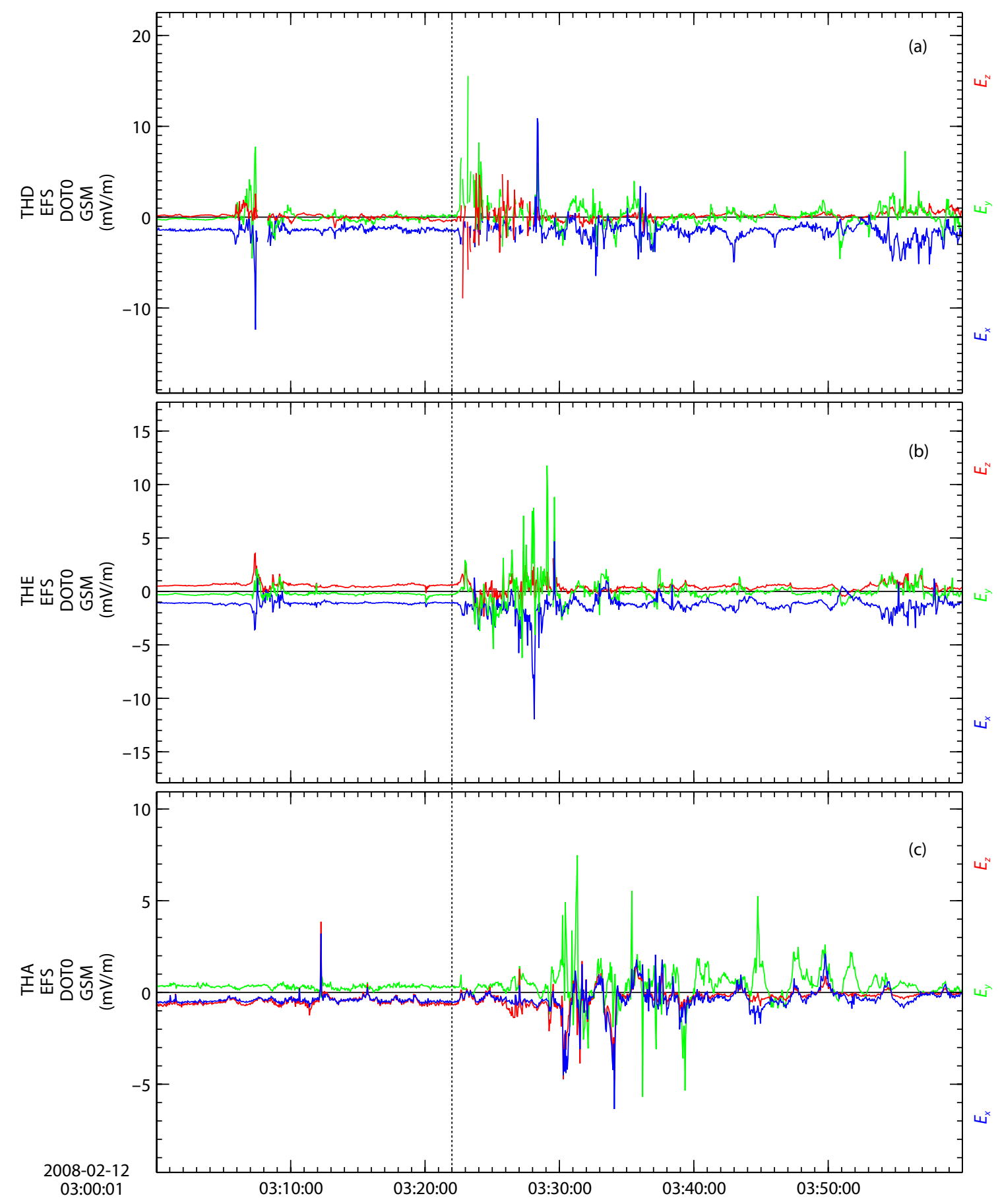

Figure 6. Electric field data from THD (P3), THE (P4) and THA (P5) during the substorm at 03:23 UT on 12 February 2008.

vals of 03:22:00 UT to 03:28:30 UT detected by THD in the substorm onset region is presented in Figure 9. We can find that the frequency range of these magnetic fluctuations is dominated in Pi1 ultralow frequency (ULF) waves ranging from $0.025 \mathrm{~Hz}$ to 0.2 $\mathrm{Hz}$. Rae et al. (2014) reported that ULF waves in the Pi1 band (1-40 s period) were traditionally used to study the specifics of the region of substorm onset; this report is consistent with our results.

It should be noted that this ideal event was selected since the THEMIS probes were located at different central plasma sheet regions in the $Z$ direction. According to the $B_{x}$ component, elevation angle and plasma beta value, we identify that THD (P3) is loc- ated at the inner edge of current sheet with very weak $B_{x}$ and $B_{y}$ components around zero. The $B_{z}$ component approaches the total magnetic field magnitude which is very small, $B_{\mathrm{t}}<10 \mathrm{nT}$, as shown in Figure $3 e$ and $3 f$, respectively. These features all demonstrate that THD (P3) is located in the current sheet. THE (P4) is locatednorthward ofthecurrentsheetwith positive $B_{x}$ component $\sim 5 \mathrm{nT}$, and large plasma beta value, $\beta \sim 2$. On the other hand, THA (P5) is located southward of the current sheet with large negative $B_{x} \sim$ $-20 \mathrm{nT}$, and $\beta \sim 1$; THA is farther from the current sheet than THE in the $Z$ direction. The locations of the three THEMIS probes and substorm onset are all illustrated in the cartoon in Figure 10. Previ- 


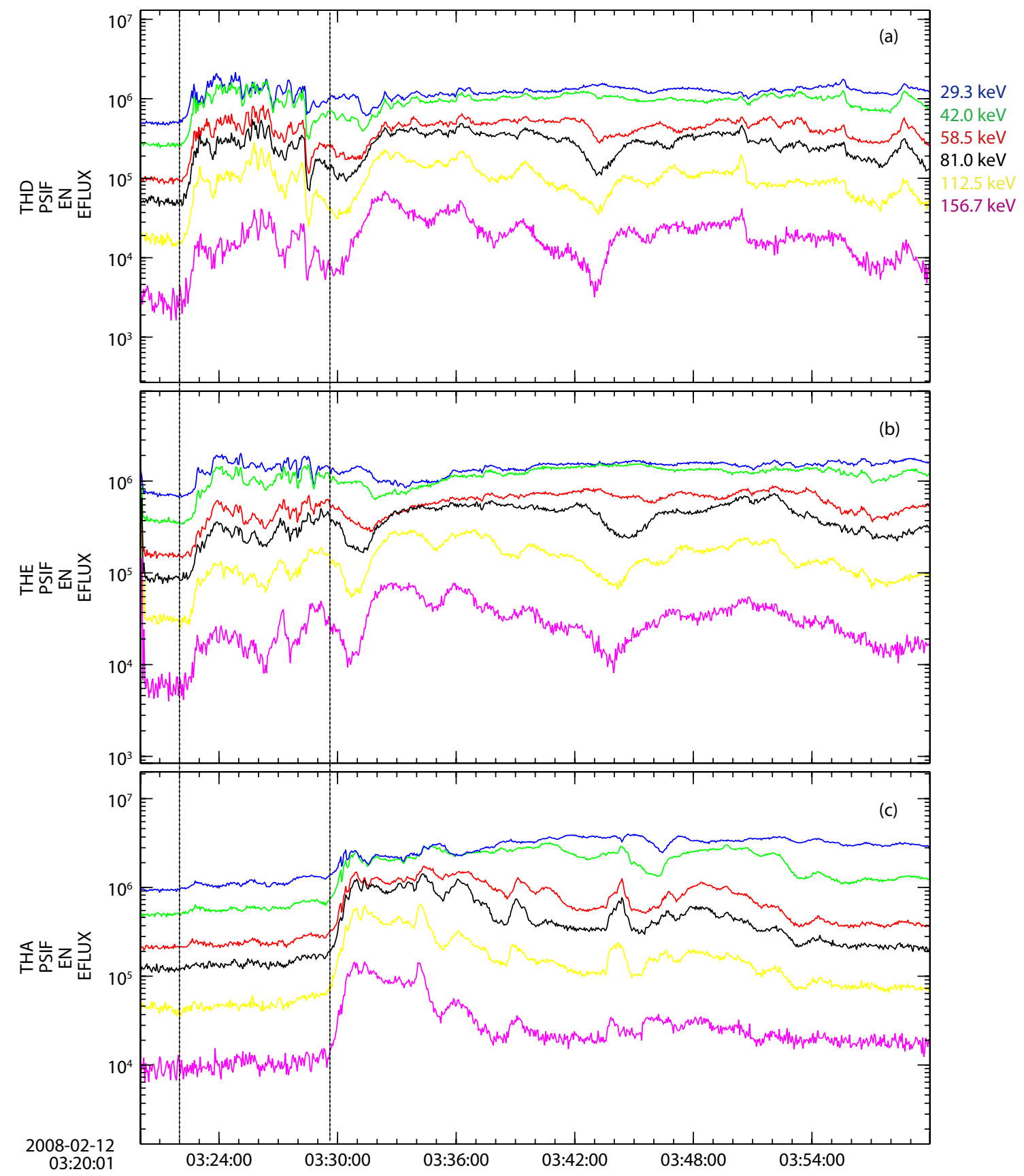

Figure 7. THEMIS observations of energetic ion dispersionless injection at in situ substorm onset 03:22 UT (THD), and dispersion injection around expansion phase enhancement at 03:29:30 UT for THD, THE, and THA.

ous statistical studies indicated that substorm onset location was mainly distributed at pre-midnight with MLT 2300 and Mlat 66.4 degrees (Frey et al., 2004). Our investigations show that THD (P3) is located in the inner edge of the NECS at pre-midnight with $M L T \sim 2300$, invariant latitude $\sim 72.7$ degrees, and it precisely detects substorm onset features. Based on these three probes' positions in the $Y$ direction, we find that THD and THE are located at pre-midnight with positive $Y \sim 2.7 R_{\mathrm{E}}$ and $3.5 R_{\mathrm{E}}$, respectively. In contrast, THA is located at post-midnight with negative $Y \sim$ $-0.3 R_{\mathrm{E}}$. Thus these three near-Earth THEMIS probes were located from $X \sim-9.1 R_{\mathrm{E}}$ to $X \sim-10.5 R_{\mathrm{E}}$ facilitating detection of the substorm onset region at the inner edge of the NECS. The THD, THE and THA probes were located within the current sheet, northward, and southward of the current sheet, respectively. The distinct orbits are such that THD (P3) is located in the current sheet with $B_{X} \sim 0 \mathrm{nT}$ and very small magnitude $B_{\mathrm{t}}<10 \mathrm{nT}$, as shown in Figure $3 \mathrm{~d}$ and $3 \mathrm{f}$. THE (P4) is located in the northern plasma sheet outside the current sheet with $B_{x} \sim 5 \mathrm{nT}$ and small magnitude of $B_{\mathrm{t}}$ $\sim 12 \mathrm{nT}$ as shown in Figure $4 \mathrm{~d}$ and $4 \mathrm{f}$. THA (P5) is located in the southern plasma sheet outside the current sheet with $B_{x} \sim-15 \mathrm{nT}$ and large magnitude $B_{\mathrm{t}} \sim 20 \mathrm{nT}$, as shown in Figure $5 \mathrm{~d}$ and $5 \mathrm{f}$. These three near-Earth probes' simultaneous detection can provide an approximate calculation for the spatial scale size of the location of substorm onset in the near-Earth tail. In our investiga- 


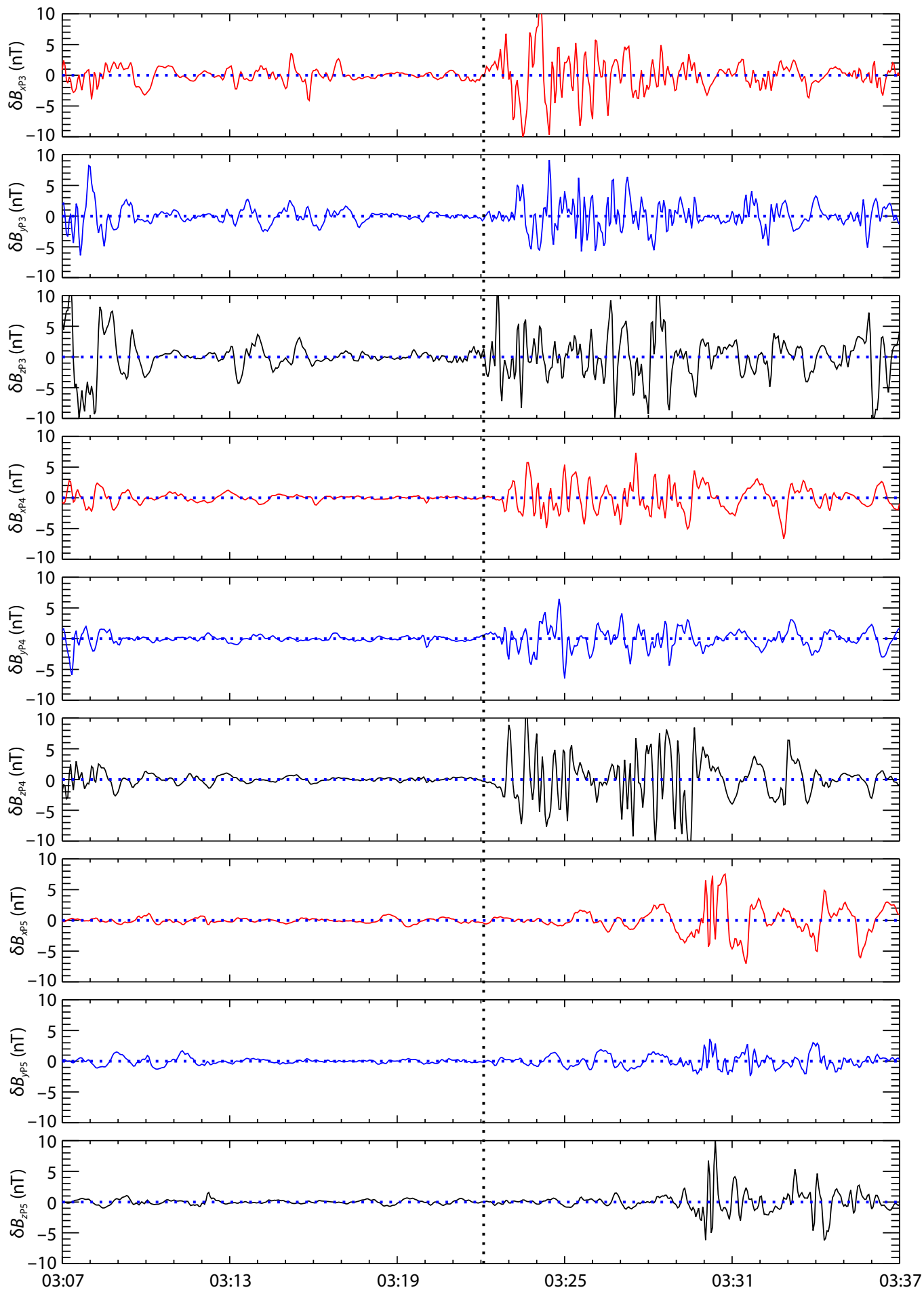

Figure 8. The broadband magnetic field fluctuations of the $B_{x}, B_{y}$ and $B_{z}$ components observed by THD (P3), THE (P4) and THA (P5) during the substorm at 03:23 UT on 12 February 2008, respectively.

tion, the smallest spatial size of the substorm onset region is about $0.9 R_{\mathrm{E}}$ in the $X$ direction, $0.7 R_{\mathrm{E}}$ in the $Y$ direction, and $0.4 R_{\mathrm{E}}$ in the $Z$ direction, based on the parameters from the THD and THE probes.

Previous substorm studies have suggested that the substorm expansion onset region is located on dipole-like field lines near the Earth at $X \sim-10 R_{\mathrm{E}}$ (e.g., Kaufmann, 1987; Samson et al., 1992; Lui et al., 1999; Rae et al., 2009, 2014). Samson et al. (1992) proposed that FLR played a role in substorm intensifications. Thus, magnetic elevation angles in the substorm onset location in the dipolelike magnetic field line region may have large beginning angles. Our results show that the beginning elevation angles of the dipolarization within the substorm onset region, at THD (P3) location with $M L T \sim 23.0$, Mlat $\sim 8.8$ degree, is large as $\theta \sim 70^{\circ}$, as shown in Figure $3 \mathrm{~g}$ at the onset time marked by the first red dot- 

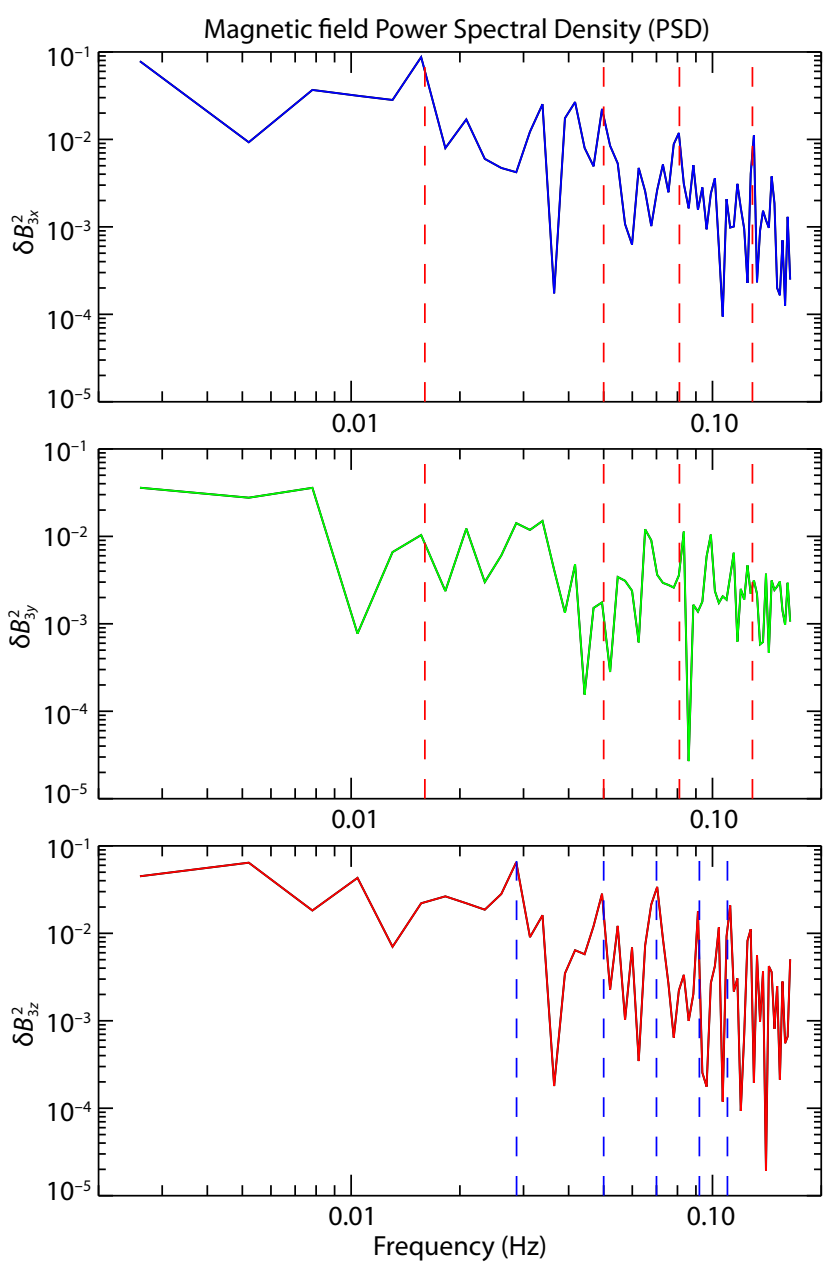

Figure 9. The magnetic field power spectral density observed by THD from 03:22:00 UT to 03:28:30 UT on 12 Feb. 2008.

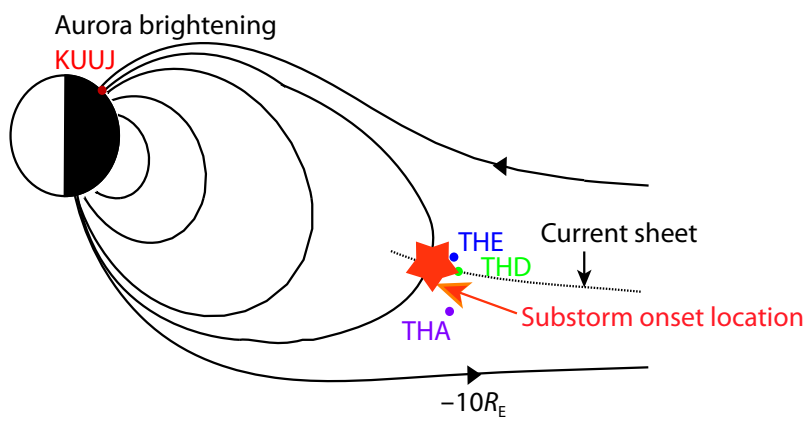

Figure 10. Cartoon for dipolarizations observed by the three nearEarth THEMIS probes in the vicinity of the substorm onset location.

ted vertical line, 03:22 UT. Auroral substorm onset observed at the ground station KUUJ with $M L T \sim 23.2$ and invariable latitude $66.9^{\circ}$ occurred at 03:23UT. Dipolarization within the substorm onset region was observed $\sim 1$ min prior to auroral brightening onset observed at KUUJ. This interval time is associated with Alfvén transit time from the substorm onset region to the footprint ionosphere (e.g., Liou et al., 2002). Smith et al. (2020) reported that the travel time from the spacecraft to the ground is about 1-2 min for ULF waves in the near-Earth magnetotail. But outside the substorm onset region, the beginning magnetic elevation is smaller than that within the substorm onset region shown in Figure $4 \mathrm{~g}, \theta \sim 45^{\circ}$ and Figure $5 \mathrm{~g}, \theta \sim 30^{\circ}$, respectively. The conjunction observations of substorm dipolarization by THEMIS' multiple probes in the near-Earth magnetotail provide evidence that the substorm expansion onset is triggered at the inner edge of the current sheet near the Earth.

However these conjunction observations also illustrate that there are significantly different features of magnetic elevation angle among these three near-Earth THEMIS probes during magnetic dipolarization from the beginning at 03:22 UT to the enhancement at 03:30 UT. The initial magnetic dipolarization elevation angle is very large $(\theta \sim 70$ degree $)$ in the substorm onset region. This magnetic dipolarization is accompanied by energetic ion dispersionless injection detected by THD (P3) at 03:22 UT, shown in Figure $3 \mathrm{~g}$ and Figure $7 \mathrm{a}$, respectively. However the elevation angle is very small far away from the substorm onset region, as detected by THA (P5) around 03:22 UT, $\theta \sim 30$ degree. The magnetic dipolarization in the outer side of the substorm onset region has a multi-step increase in the elevation angle, whose maximum value approaches $70^{\circ}$ as shown in Figure $5 \mathrm{~g}$. According to these differences between the magnetic dipolarizations in the nearEarth magnetotail, we can use the evident point of the magnetic elevation angle within the substorm onset region (the large beginning angle around $70^{\circ}$ and followed by significant fluctuations) as an indicator of the substorm onset triggering location in the magnetotail.

Substorm enhancement during the substorm expansion phase is a large spatial scale phenomenon. Based on THEMIS observations the substorm enhancement took place at 03:30UT as marked by the black dashed lines, in Figures $3-5$, the $B_{z}$ component and magnetic elevation angle both increase at different locations in the magnetotail. At substorm enhancement time, three nearEarth THEMIS probes were located at $(-10.39,2.80,-2.56) R_{\mathrm{E}}(\mathrm{P} 3)$, $(-9.48,3.44,-2.22) R_{\mathrm{E}}(\mathrm{P} 4),(-9.05,-0.27,-3.08) R_{\mathrm{E}}(\mathrm{P} 5)$, respectively. Thus substorm enhancement has a large spatial scale size of several $R_{\mathrm{E}}$. The multi-step increases in the $B_{z}$ component and elevation angle last about $10 \mathrm{~min}$, as shown in Figure $5 \mathrm{e}$ and Figure $5 \mathrm{~g}$. After the substorm enhancement the maximum value of the magnetic dipolarization elevation angle is different at these three probes: $\theta_{\max }$ is $\sim 85^{\circ}$ at P3 (THD) in the current sheet, $\theta_{\max }$ $\sim 80^{\circ}$ at $\mathrm{P} 4$ (THE) northward of the current sheet, and then steady at $\theta \sim 70^{\circ}$. $\theta_{\max }$ is $\sim 70^{\circ}$ with multi-step increases at P5 (THA) southward of the current sheet. This means that during the later substorm expansion phase, the plasma sheet is symmetric to the current sheet.

\section{Summary}

As mentioned above, the spatial and temporal properties of substorm dipolarizations during a substorm on 12 February 2008 are investigated with in situ observations at the different locations of three THEMIS probes, THD (P3) at the inner edge of the current sheet, THE (P4) northward of the central plasma sheet, and THA (P5) southward of the plasma sheet in the near-Earth magnetotail. At the inner edge of the NECS with high plasma beta, $\beta>2$, the dipolarization within the substorm onset region has a large beginning magnetic elevation angle, $\theta \sim 70^{\circ}$, following significant fluc- 
tuations and accompanied with energetic ion dispersionless injection. The maximum value of this dipolarization elevation angle approaches $85^{\circ}$ during the later substorm expansion phase. Further, dipolarization within the substorm onset region is characterized by significant fluctuations with broadband frequency. In addition, $B_{z}$ is the dominant component and its magnitude approaches the total magnetic field value, $B_{\mathrm{t}}$. The $B_{z}$ component has large amplitude oscillations, occasionally with negative value. This dipolarization is proposed as a new indicator to identify the substorm onset location in the magnetotail.

In the NEPS where $\beta \sim 1$, the dipolarization outside the substorm onset region is characterized by a magnetic elevation angle with low beginning value, $<45^{\circ}$, and followed by multi-step enhancements during the substorm expansion phase. The maximum value of the elevation angle approaches $70^{\circ}$ during the later substorm expansion phase.

Conjunction in situ observation results indicate that the dipolarization within the substorm onset region is accompanied by significant fluctuations with broadband frequency. The dipolarization outside the substorm onset region is characterized by multi-step increases in the magnetic elevation angle. Moreover, the dipolarization associated with substorm enhancements during the substorm expansion phase has a large spatial (several $R_{\mathrm{E}}$ ) and temporal scale (tens of minutes). Our results present distinct spatial-temporal properties of substorm dipolarizations in the near-Earth magnetotail. Dipolarization characteristics within the substorm onset region are proposed as a new indicator to identify the substorm onset location in the magnetotail.

\section{Acknowledgments}

We acknowledge NASA contract NAS5-02099 and V. Angelopoulos for use of data from the THEMIS mission. Specifically: "D. Larson and R. P. Lin for use of SST data, C. W. Carlson and J. P. McFadden for use of ESA data, J. Bonnell and F.S.Mozer for use of the EFI data; K. H. Glassmeier, U. Auster and W. Baumjohann for the use of FGM data provided under the lead of the Technical University of Braunschweig and with financial support through the German Ministry for Economy and Technology and the German Center for Aviation and Space (DLR) under contract 50 OC 0302, S. Mende and E. Donovan for the use of ASI data, and the CSA for logistical support in fielding and data retrieval from the GBO stations." We gratefully acknowledge THEMIS data obtained online (https://themis.ssl.berkeley.edu/) and the Kyoto World Data Center for providing the $\mathrm{AE}, \mathrm{AL}$ and $\mathrm{AU}$ indices (http://wdc.kugi.kyotou.ac.jp/aeasy/). This work was supported by the National Natural Science Foundation of China (NSFC) under grants 41731070, 41674167,41574161 , the Strategic Pioneer Program on Space Science, Chinese Academy of Sciences, grants XDA15052500, XDA15350201 and XDA15011401; and in part by the Specialized Research Fund for State Key Laboratories of China.

\section{References}

Angelopoulos, V. (2008). The THEMIS Mission. Space Sci. Rev., 141(1-4), 5-34. https://doi.org/10.1007/s11214-008-9336-1

Auster, H. U., Glassmeier, K. H., Magnes, W., Aydogar, O., Baumjohann, W., Constantinescu, D., Fischer, D., Fornacon, K. H., Georgescu, E., ...
Wiedemann, M. (2008). The THEMIS fluxgate magnetometer. Space Sci. Rev., 141(1-4), 235-264. https://doi.org/10.1007/s11214-008-9365-9

Baumjohann, W., Hesse, M., Kokubun, S., Mukai, T., Nagai, T., and Petrukovich, A. A. (1999). Substorm dipolarization and recovery. J. Geophys. Res., 104(A11), 24995-25000. https://doi.org/10.1029/1999JA900282

Bonnell, J. W., Mozer, F. S., Delory, G. T., Hull, A. J., Ergun, R. E., Cully, C. M., Angelopoulos V., and Harvey, P. R. (2008). The electric field instrument (EFI) for THEMIS. Space Sci. Rev., 141(1-4), 303-341. https://doi.org/10.1007/s11214-008-9469-2

Cao, J. B., Ma, Y. D., Parks, G., Reme, H., Dandouras, I., Nakamura, R., Zhang, T. L., Zong, Q., Lucek, E., ... Zhou, C. C. (2006). Joint observations by Cluster satellites of bursty bulk flows in the magnetotail. J. Geophys. Res., 111(A4), A04206. https://doi.org/10.1029/2005JA011322

Cao, J. B., Ding, W. Z., Reme, H., Dandouras, I., Dunlop, M., Liu, Z. X., and Yang, J. Y. (2011). The statistical studies of the inner boundary of plasma sheet. Ann. Geophys., 29(2), 289-298. https://doi.org/10.5194/angeo-29-289-2011

Dai, L., Wygant, J. R., Cattell, C. A., Thaller, S., Kersten, K., Breneman, A., Tang, X. W., Friedel, R. H., Claudepierre, S. G., and Tao, X. (2014). Evidence for injection of relativistic electrons into the Earth's outer radiation belt via intense substorm electric fields. Geophys. Res. Lett., 41(4), 1133-1141. https://doi.org/10.1002/2014GL059228

Dai, L., Wang, C., Duan, S. P., He, Z. H., Wygant, J. R., Cattell, C. A., Tao, X., Su, Z. P., Kletzing, C., ... Tang, X. W. (2015). Near-Earth injection of MeV electrons associated with intense dipolarization electric fields: Van Allen Probes observations. Geophys. Res. Lett., 42(15), 6170-6179. https://doi.org/10.1002/2015GL064955

Duan, A. Y., Cao, J. B., Dunlop, M., and Wang, Z. Q. (2014). Energetic electron bursts in the plasma sheet and their relation with BBFs. J. Geophys. Res., 119(11), 8902-8915. https://doi.org/10.1002/2014JA020169

Duan, S. P., Liu, Z. X., Liang, J., Zhang, Y. C., and Chen, T. (2011). Multiple magnetic dipolarizations observed by THEMIS during a substorm. Ann. Geophys., 29(2), 331-339. https://doi.org/10.5194/angeo-29-331-2011

Duan, S. P., Liu, Z. X., and Angelopoulos, V. (2012). Observations of kinetic Alfvén waves by THEMIS near a substorm onset. Chin. Sci. Bull., 57(12), 1429-1435. https://doi.org/10.1007/s11434-012-4973-x

Duan, S. P., Dai, L., Wang, C., Liang, J., Lui, A. T. Y., Chen, L. J., He, Z. H., Zhang, Y. C., and Angelopoulos, V. (2016). Evidence of kinetic Alfvén eigenmode in the near-Earth magnetotail during substorm expansion phase. J. Geophys. Res., 121(5), 4316-4330. https://doi.org/10.1002/2016JA022431

Frey, H. U., Mende, S. B., Angelopoulos, V., and Donovan, E. F. (2004). Substorm onset observations by IMAGE-FUV. J. Geophys. Res., 109(A10), A10304. https://doi.org/10.1029/2004JA010607

Fu, H. S., Khotyaintsev, Y. V., Vaivads, A., André, M., and Huang, S. Y. (2012). Occurrence rate of earthward-propagating dipolarization fronts. Geophys. Res. Lett., 39(10), L10101. https://doi.org/10.1029/2012GL051784

He, Z. H., Dai, L., Wang, C., Duan, S. P., Zhang, L. Q., Chen, T., and Roth, I. (2016). Contributions of substorm injections to SYM-H depressions in the main phase of storms. J. Geophys. Res., 121(12), 11729-11736. https://doi.org/10.1002/2016JA023218

Kaufmann, R. L. (1987). Substorm currents: growth phase and onset. J. Geophys. Res., 92(A7), 7471-7486. https://doi.org/10.1029/JA092iA07

Liang, J., Donovan, E. F., Liu, W. W., Jackel, B., Syrjäsuo, M., Mende, S. B., Frey, H. U., Angelopoulos, V., and Connors, M. (2008). Intensification of preexisting auroral arc at substorm expansion phase onset: wave-like disruption during the first tens of seconds. Geophys. Res. Lett., 35(17), L17S19. https://doi.org/10.1029/2008GL033666

Liang, J., Liu, W. W., Donovan, E. F., and Spanswick, E. (2009). In-situ observation of ULF wave activities associated with substorm expansion phase onset and current disruption. Ann. Geophys., 27(5), 2191-2204. https://doi.org/10.5194/angeo-27-2191-2009

Liou, K., Meng, C. I., Lui, A. T. Y., Newell, P. T., and Wing, S. (2002). Magnetic dipolarization with substorm expansion onset. J. Geophys. Res., 107(A7), 1131. https://doi.org/10.1029/2001JA000179

Liu, C. M., and Fu, H. S. (2019). Anchor point of electron acceleration around dipolarization fronts in space plasmas. Astrophys. J. Lett., 873(1), L2. https://doi.org/10.3847/2041-8213/ab06cb 
Liu, W. W., Liang, J., Spanswick, E., and Donovan, E. F. (2007). Remote-sensing magnetospheric dynamics with riometers: observation and theory. $J$. Geophys. Res., 112(A5), A05214. https://doi.org/10.1029/2006JA012115

Lui, A. T. Y., and Burrows, J. R. (1978). On the location of auroral arcs near substorm onsets. J. Geophys. Res., 83(A7), 3342-3348. https://doi.org/10.1029/JA083iA07p03342

Lui, A. T. Y. (1996). Current disruption in the Earth's magnetosphere: observations and models. J. Geophys. Res., 101(A6), 13067-13088. https://doi.org/10.1029/96JA00079

Lui, A. T. Y., Liou, K., Nosé, M., Ohtani, S., Williams, D. J., Mukai, T., Tsuruda, K., and Kokubun, S. (1999). Near-Earth dipolarization: evidence for a non-MHD process. Geophys. Res. Lett., 26(19), 2905-2908. https://doi.org/10.1029/1999GL003620

Lui, A. T. Y., Volwerk, M., Dunlop, M. W., Alexeev, I. V., Fazakerley, A. N., Walsh, A. P., Lester, M., Grocott, A., Mouikis, C., and Rème, H. (2008). Near-Earth substorm features from multiple satellite observations. J. Geophys. Res., 113(A7), A07S26. https://doi.org/10.1029/2007JA012738

Maynard, N. C., Burke, W. J., Basinska, E. M., Erickson, G. M., Hughes, W. J., Singer, H. J., Yahnin, A. G., Hardy, D. A., and Mozer, F. S. (1996). Dynamics of the inner magnetosphere near times of substorm onsets. J. Geophys. Res., 101(A4), 7705-7736. https://doi.org/10.1029/95JA03856

McFadden, J. P., Carlson, C. W., Larson, D., Ludlam, M., Abiad, R., Elliott, B., Turin, P., Marckwordt, M., and Angelopoulos, V. (2008). The THEMIS ESA plasma instrument and in-flight calibration. Space Sci. Rev., 141(1-4), 277-302. https://doi.org/10.1007/s11214-008-9440-2

Nagai, T. (1982). Observed magnetic substorm signatures at synchronous altitude. J. Geophys. Res., 87(A6), 4405-4417. https://doi.org/10.1029/JA087iA06p04405

Nakamura, R., Baumjohann, W., Klecker, B., Bogdanova, Y., Balogh, A., Rème, H., Bosqued, J. M., Dandouras, I., Sauvaud, J. A., and Runov, A. (2002). Motion of the dipolarization front during a flow burst event observed by Cluster. Geophys. Res. Lett., 29(20), 1942. https://doi.org/10.1029/2002GL015763

Nakamura, R., Retinò, A., Baumjohann, W., Volwerk, M., Erkaev, N., Klecker, B., Lucek, E. A., Dandouras I., André, M., and Khotyaintsev, Y. (2009). Evolution of dipolarization in the near-Earth current sheet induced by Earthward rapid flux transport. Ann. Geophys., 27(4), 1743-1754. https://doi.org/10.5194/angeo-27-1743-2009

Rae, I. J., Mann, I. R., Angelopoulos, V., Murphy, K. R., Milling, D. K., Kale, A., Frey, H. U., Rostoker, G., Russell, C. T., ... Donovan, E. F. (2009). Near-Earth initiation of a terrestrial substorm. J. Geophys. Res., 114(A7), A07220. https://doi.org/10.1029/2008JA013771

Rae, I. J., Murphy, K. R., Watt, C. E. J., Rostoker, G., Rankin, R., Mann, I. R., Hodgson, C. R., Frey, H. U., Degeling, A. W., and Forsyth, C. (2014). Field line resonances as a trigger and a tracer for substorm onset. J. Geophys. Res., 119(7), 5343-5363. https://doi.org/10.1002/2013JA018889

Reeves, G. D., Fritz, T. A., Cayton, T. E., and Belian, R. D. (1990). Multi-satellite measurements of the substorm injection region. Geophys. Res. Lett., 17(11), 2015-2018. https://doi.org/10.1029/GL017i011 p02015

Runov, A., Angelopoulos, V., Sitnov, M. I., Sergeev, V. A., Bonnell, J., McFadden, J. P., Larson, D., Glassmeier, K. H., and Auster, U. (2009). THEMIS observations of an earthward-propagating dipolarization front. Geophys. Res. Lett., 36(14), L14106. https://doi.org/10.1029/2009GL038980

Samson, J. C., Wallis, D. D., Hughes, T. J., Creutzberg, F., Ruohoniemi, J. M., and Greenwald, R. A. (1992). Substorm intensifications and field line resonances in the nightside magnetosphere. J. Geophys. Res., 97(A6), 8495-8518. https://doi.org/10.1029/91JA03156

Smith, A. W., Rae, I. J., Forsyth, C., Watt, C. E. J., Murphy, K. R., and Mann, I. R. (2020). Diagnosing the time-dependent nature of magnetosphereionosphere coupling via ULF waves at substorm onset. J. Geophys. Res., 125(11), e2020JA028573. https://doi.org/10.1029/2020JA028573

Sun, X. Y., Liu, W. W., and Duan, S. P. (2019). Magnetic dipolarizations inside geosynchronous orbit with tailward ion flows. Ann. Geophys., 37(3), 289-297. https://doi.org/10.5194/angeo-37-289-2019

Takahashi, K., Zanetti, L. J., Lopez, R. E., McEntire, R. W., Potemra, T. A., and Yumoto, K. (1987). Disruption of the magnetotail current sheet observed by AMPTE/CCE. Geophys. Res. Lett., 14(10), 1019-1022. https://doi.org/10.1029/GL014i010p01019

Wharton, S. J., Wright, D. M., Yeoman, T. K., James, M. K., and Sandhu, J. K. (2019). The variation of resonating magnetospheric field lines with changing geomagnetic and solar wind conditions. J. Geophys. Res., 124(7), 5353-5375. https://doi.org/10.1029/2019JA026848 